\title{
Transient Leukemoid Reaction of the Newborn
}

National Cancer Institute

\section{Source}

National Cancer Institute. Transient Leukemoid Reaction of the Newborn. NCI

Thesaurus. Code C101319.

Increased white blood cell count and increased neutrophil precursors resembling leukemia in a neonate or fetus. Often, this is a response to medications received, infection or Down syndrome. 